\title{
Who Is Responsible for a Nursing Home Resident's Daily Oral Care?
}

$\mathbf{I}^{\mathrm{n}}$ their article, "Hand function and oral hygiene in Brazilian institutionalized elderly," Padilha et al. ${ }^{1}$ call attention to a critically important yet undervalued issue of nursing home care: the risk that care providers are ignoring self-care and instrumental activities that are not identified as activities of daily living or picked up through performance measures. Although this was not the central thrust of their investigation, it is a key message that should be extrapolated from the authors' findings and ought to serve as the basis for overdue action.

The study's findings may be simplistically summarized as follows: The objectively assessed eye-hand coordination of elderly institutionalized patients is correlated with ability to clean teeth and dentures effectively. This observation, independent of its geriatric implications, is practically axiomatic for dental health professionals caring for younger patients in whom trauma; acute, chronic, or progressive neurological disease; or developmental cognitive disability impairs manual dexterity. For such individuals, daily oral hygiene can variously require the modification of toothbrushes for limited range of motion or reduced grip strength, adaptation of dual-hand procedures (such as using dental floss or brushing a denture) for a single hand through wall mounts or suction cups, or providing cues and reminders; however, it is also recognized that such expedients will only be effective for a motivated patient who possesses more than minimal cognitive and neuromuscular ability. Those who do not must have someone else clean their teeth and intraoral appliances.

In this journal nearly 20 years ago, an investigation of a population of elderly Catholic sisters in Minnesota demonstrated that impaired manual dexterity was a more-powerful predictor for institutional placement than age or cognitive status. ${ }^{2}$ Because declining manual dexterity predisposes to institutionalization and, in institutionalized older people, interferes with effective oral hygiene, it is not a leap of faith, and it is certainly consistent with numerous published studies (e.g., ${ }^{3,4}$ ) and casual observation, to conclude that older people in nursing homes are likely to have poor oral hygiene.

Poor oral hygiene in nursing home residents would be less important were it not for the growing evidence that poor oral care, in addition to representing an unaesthetic condition that is antecedent to destructive dental and periodontal disease and possibly impaired nutrition, is a

DOI: $10.1111 / \mathrm{j} .1532-5415.2007 .01280 . x$ significant yet eminently manageable risk factor for the leading infectious cause of hospitalization and death in this same population: nosocomial pneumonia. ${ }^{5-7}$ Pulmonary pathogens responsible for bacterial pneumonia colonize oral plaque and pharyngeal secretions, a situation worsened by, but by no means dependent on, suppression of salivary flow and modification of salivary secretions occurring as a side effect of a wide range of medications. Pilot trials comparing elderly nursing home and hospital subjects with and without oral hygiene measures have variously demonstrated reduced morbidity, mortality, hospitalization, febrile days, and healthcare costs in the groups randomized for cleaner mouths. $^{8-11}$

There is an abundance of dental literature exploring why nurses' aides in long-term care are not more diligent in addressing their charges' oral health (e.g., ${ }^{12-14}$ ). Reasons cited include little to no instruction in the procedure, fear of being bitten or sprayed with potentially infectious oral debris, competing obligations for which underperformance is punished, low personal priority given to aides' own oral health, and personal distaste. The first two of these can be readily addressed through education and training efforts, readily accessible in several media from a variety of sources. Addressing the third of these requires a management commitment that would make moot the fourth and fifth. Yet in the current U.S. long-term care economic and regulatory climate, elevating the importance of oral care to that of other nursing care activities requires the development, tracking, and enforcement of underachievement in one or more performance indicators. The Minimum Data Set, which dictates much of long-term care practice in America and elsewhere, presently includes some attention to oral health, ${ }^{15}$ yet because the data collected do not feed into the performance indicators that funding agencies and regulators track, oral care is accorded little regard.

Padilha et al. ${ }^{1}$ conclude their article by suggesting that institutionalized older people with poor oral health should be assessed for hand function so that efforts to teach oral hygiene can be focused on those most likely to benefit. This is a reasonable conclusion but misses a somewhat moreimportant concern, which is that institutionalized older people with poor oral health need to have that risk status addressed, much as inability to bathe or to get out of bed safely or to maintain perineal cleanliness are assessed through the efforts of nursing staff hired for that purpose.

The authors state that "the costs of providing oral health care in long-term care facilities are high," another 
observation that is valid. Yet it should be noted that the costs for bathing, toileting, and feeding in long-term care facilities are also high. There are care providers in every long-term care facility whose job it is to address patients' unmet self-care needs so that patients' health risks are minimized. That the fulfillment of that charge typically does not include oral care but is instead limited to those needs that are closely tracked is an abrogation of responsibility on the part of nursing home clinical leadership that must be acknowledged and addressed.

\section{ACKNOWLEDGMENTS}

The opinions in this editorial are those of the author and do not reflect or represent positions or policy of the U.S. Department of Veterans Affairs. The author was the sole contributor to the editorial and has neither financial nor business arrangements relevant to topics or products discussed.

\section{Kenneth Shay, DDS, MS \\ Office of Geriatrics and Extended Care U.S. Department of Veterans Affairs Washington, D.C. Department of Periodontics/Prevention/Geriatrics School of Dentistry University of Michigan Ann Arbor, Michigan}

\section{REFERENCES}

1. Padilha DMP, Hugo FN, Hilgert JB et al. Hand function and oral hygiene in Brazilian institutionalized elderly. J Am Geriatr Soc 2007;55:1333-1338.
2. Ostwald SK, Snowdon DA, Rysavy DM et al. Manual dexterity as a correlate of dependency in the elderly. J Am Geriatr Soc 1989;37:963-969.

3. Berkey DB, Berg RG, Ettinger RL et al. Research review of oral health status and service use among institutionalized older adults in the United States and Canada. Spec Care Dentist 1991;11:131-136.

4. Terpenning MS, Taylor GW, Lopatin DE et al. Aspiration pneumonia: Dental and oral risk factors in an older veteran population. J Am Geriatr Soc 2001:49:557-563.

5. Loesche WJ, Schork A, Terpenning MS et al. Factors which influence levels of selected organisms in saliva of older individuals. Clin Microbiol 1995;33:2550-2557.

6. Scannapieco FA. The role of oral bacteria in respiratory infection. J Periodontol 1999;70:793-802.

7. Shay K, Scannapieco FA, Terpenning MT et al. Nosocomial pneumonia and oral health. Spec Care Dentist 2005;25:179-187.

8. Yoneyama T, Hashimoto K, Fukuda $\mathrm{H}$ et al. Oral hygiene reduces respiratory infections in elderly bed-bound nursing home patients. Arch Gerontol Geriatr 1996;22:11-19.

9. Yoneyama T, Yoshida M, Ohrui $\mathrm{T}$ et al. Oral care reduces pneumonia in older patients in nursing homes. J Am Geriatr Soc 2002;50:430-433.

10. Adachi M, Ishihara K, Abe $\mathrm{S}$ et al. Effect of professional oral health care on the elderly living in nursing homes. Oral Surg Oral Med Oral Pathol Oral Radiol Endod 2002;94:191-195.

11. Bergmans DC, Bonent MJ, Gaillard CA et al. Prevention of ventilator-associated pneumonia by oral decontamination. A prospective, randomized, double-blind, placebo-controlled study. Am J Respir Crit Care Med 2001;164:382-388.

12. Chalmers JM, Levy SM, Buckwalter KC et al. Factors influencing nurses' aides' provision of oral care for nursing facility residents. Spec Care Dentist 1996;16:71-79.

13. Yoshino A, Ebihara T, Ebihara $\mathrm{S}$ et al. Daily oral care and risk factors for pneumonia among elderly nursing home patients. JAMA 2001;286:22352236.

14. Pyle MA, Jasinevicius TR, Sawyer DR et al. Nursing home executive directors' perception of oral care in long-term care facilities. Spec Care Dentist 2005;25:111-117.

15. Ettinger RL, O'Toole C, Warren J et al. Nursing directors' perceptions of the dental components of the Minimum Data Set (MDS) in nursing homes. Spec Care Dentist 2000;20:23-27. 